Original Research Article

\title{
Effects of leaf extracts of Vernonia amygdalina on the force and rate of contractility of an isolated mammalian heart
}

\author{
Godfrey S. Bbosa ${ }^{1}$, Robert Lubajo ${ }^{1}$, Aloysius M. Lubega ${ }^{1}$, Gordon Odia ${ }^{1}$, John Katerega ${ }^{2}$
}

${ }^{1}$ Department of Pharmacology and Therapeutics, Makerere University College of Health Sciences, Kampala, Uganda ${ }^{2}$ Department of Pharmacology, Makerere University College of Veterinary medicine Animal Resource and Biosecurity, Kampala, Uganda

Received: 22 August 2019

Revised: 23 September2019

Accepted: 27 September 2019

*Correspondence to:

Dr. Godfrey S. Bbosa,

Email: godfossa@gmail.com

Copyright: () the author(s), publisher and licensee Medip Academy. This is an openaccess article distributed under the terms of the Creative Commons Attribution NonCommercial License, which permits unrestricted noncommercial use, distribution, and reproduction in any medium, provided the original work is properly cited.

\begin{abstract}
Background: Vernonia amygdalina is a common medicinal plant that is widely used by local communities and traditional herbalists in central Uganda in the management of various conditions including hypertension that occurs as a result of changes in heart contractility. However, there is limited scientific information of $V$. amygdalina effects on the force and rate of contractility of the heart. The study evaluated the inotropic and chronotropic effect of methanol, aqueous, ether and total crude leaf extracts of $V$. amygdalina on isolated perfused rabbit heart.

Methods: An experimental laboratory based study determined the effects of $V$. amygdalina extracts on the rate and force of contraction isolated perfused rabbit using the Langendorff's heart perfusion experiment and methods. The heart rate (beats/minute) was counted per minute. The force of the contraction of the heart was determined by measuring the height of each peak on the kymogram.

Results: The findings showed that the force and rate of heart contractility reduced with increasing doses of methanol, aqueous, ether and total crude leaf extracts at doses of $0.5,8.0,62.0$ and $250.0 \mathrm{mg} / \mathrm{ml}$ respectively. The force and rate of heart contractility at a dose of $250.0 \mathrm{mg} / \mathrm{ml}$ for all the extracts were comparable to that of acetylcholine drug to almost causing cardiac arrest.

Conclusions: The leaf extracts of $V$. amygdalina contain compounds that reduced the force and rate of contraction of an isolated perfused rabbit heart.
\end{abstract}

Keywords: Isolated mammalian heart, Contractility, Inotropic and chronotropic, Langendorff's heart perfusion, Vernonia amygdalina

\section{INTRODUCTION}

Herbs have for long been used in the management of various diseases including high blood pressure (hypertension) in the various communities of the world, which is among the major cause of death and disability. ${ }^{1-7}$ In Uganda, hypertension is a serious public health problem with regional variation. ${ }^{4,8}$ In the local communities and among traditional herbalist, various medicinal plants are utilized in management of hypertension. $^{2,9-12}$ These plants contain a number secondary metabolites including sulforaphane, tocotrienols, resveratrol, dios-genin, isoflavones, carotenoids, flavonoids like quercetin and catechin with protective effects on heart. ${ }^{13-15}$ Vernonia amygdalina medicinal plant is a common herb in Uganda and used as food and as a medicine. ${ }^{10,16,17}$ It is used in management of hypertension, fever, malaria, diarrhea and many others., ${ }^{2,9-}$ 12,17 The plant contains a number of phytochemical compounds including alkaloids, phenolic acids, flavonoids, carotenoids, steroids and terpenoids, anthraquinones, saponins, coumarins, xanthones, lignans, edotides and sesquiterpene lactones. ${ }^{10,13,14,16,18-20}$ In addition, the plant is also rich in various nutrients and minerals including calcium $(\mathrm{Ca})$, magnesium $(\mathrm{Mg})$, potassium $(\mathrm{K})$, sodium $(\mathrm{Na})$, manganese $(\mathrm{Mn})$, iron $(\mathrm{Fe})$, zinc $(\mathrm{Zn})$, selenium $(\mathrm{Se})$ and copper $(\mathrm{Cu})$; vitamins $\mathrm{B} 1$, B2, B6, niacin, $\mathrm{C}, \mathrm{E}$ and folic acid with different 
nutritional and medicinal properties. ${ }^{18,20,21}$ However, previous studies show that the plant has a very high $\mathrm{K}^{+}$ concentrations compared to other minerals and $\mathrm{K}^{+}$ion causes hyperpolarization of the myocardial cells hence leading to reduced force and rate of heart contractility. ${ }^{18,21-23}$ However, there is limited scientific information on its effects on reducing the rate and force of contraction on the heart and hence its utilization by local communities and traditional herbalist in management sustained high blood pressure (hypertension). The study investigated the effects of methanol, aqueous, ether and total crude leaf extracts of $V$. amygdalina on the rate and force of contraction of the isolated perfused rabbit heart.

\section{METHODS}

\section{Study design}

Experimental laboratory based study was conducted to determine the effect of leaf extract of $V$. amygdalina on the rate and force of contractility of an isolated rabbit heart using the Langendorff's heart perfusion methods of experiment during the period of March to May 2005 at Pharmacology laboratory in the department of Pharmacology and Therapeutics, Makerere University College of Health Sciences. ${ }^{24-26}$

\section{Medicinal plant selection}

The $V$. amygdalina was selected basing on ethnobotanical surveys and local indigenous knowledge on its use in management of sustained high blood pressure (hypertension). ${ }^{2,11,12}$

\section{Medicinal plant collection, identification and processing}

The plant leaves were collected from Kawempe division in Kampala district in central Uganda using standard methods and was authenticated at the Makerere University Herbarium by a taxonomist with a voucher number of 001 which was deposited at the herbarium for future references. The leaves were dried in a solar drier until a constant weight was attained and then were pounded into powder using mortar and pestle.

\section{Extraction process}

To about $500 \mathrm{~g}$ in a flat bottomed flask, $1500 \mathrm{ml}$ of ether was added and left soaked for three days with daily agitation. It was then filtered into a clean flat bottomed flask using Whatman filter paper No.1 in a Buchner funnel. The filtrate was kept for solvent recovery. The residue was air-dried for 1 hour and the process was repeated using $1500 \mathrm{ml}$ of $99.8 \%$ methanol solvent. The process was finally repeated using the distilled water to produce aqueous leaf extract but $100 \mathrm{ml}$ of $70 \%$ ethanol was added to prevent fungal attack. The ether and methanol solvents were recovered using a rotary evaporator (Buchi, RotorVap R model R-205, BÜCHI
Labortechnik AG Flawil, Switzerland) to produce semisolid ether and methanol extracts respectively. The dry aqueous extract was obtained by use of laboratory freeze dryer VaCo 5 (ZIRBUS technology GmbH, Bad Grund / Harz, Germany). An equal amount $(0.5 \mathrm{~g})$ of the semisolid ether, methanol and aqueous extracts were uniformly mixed to produce the total crude leaf extract. These extracts were then put in small dark bottles and further air dried at room temperature to produce dry extracts that were used in the experimental study.

\section{Selection and treatment of experimental animals}

The animals selected was at least above $1.6 \mathrm{~kg}$ body weight and heart weight about $8-9 \mathrm{~g}$ as per the method guideline. ${ }^{24}$ Three normal, healthy, non-pregnant, nonnursing mature (10 weeks) hybrid rabbits were purchased from local vendors but only one with viable heart was used. The animals were treated humanely according to international guidelines on laboratory animal use according to OECD (2001) test no $420{ }^{27}$ They were provided with food pellets from Engano Millers Limited (Nuvita), Kampala, Uganda and clean water adlib. They were allowed to acclimatize for a period of two weeks before the experiment commenced. ${ }^{27,28}$

\section{Preparation of stock solutions and different doses of the plant extract, adrenaline and acetylcholine solutions}

To $1 \mathrm{~g}$ of each of the ether, methanol, aqueous and total crude dry leaf extracts of $V$. amygdalina were dissolved in a few drops of dimethylsulfoxide (DMSO) and topped up with Locke's solution to obtain a stoke solution of $1000.0 \mathrm{mg} / \mathrm{ml}$ for each extract. Serial dilutions were then made using the same solution to obtain concentrations of $0.5 \mathrm{mg} / \mathrm{ml}, 8.0 \mathrm{mg} / \mathrm{ml}, 62.0 \mathrm{mg} / \mathrm{ml}$, and $250.0 \mathrm{mg} / \mathrm{ml}$ that were used in the experimental study. The epinephrine and acetylcholine were obtained from Sigma Deduich. Co., Desenhofen, Germany and these were used as negative and positive controls respectively. To $0.1 \mathrm{~g}$ of acetylcholine, was added $10 \mathrm{ml}$ of Locke's solution to obtain a concentration of $10.0 \mathrm{mg} / \mathrm{ml}$ which was diluted to obtain concentrations of $1.0 \mathrm{mg} / \mathrm{ml}$ that was serially diluted to obtained concentrations of $0.03 \mathrm{mg} / \mathrm{ml}, 0.06$ $\mathrm{mg} / \mathrm{ml}, 0.13 \mathrm{mg} / \mathrm{ml}, 0.25 \mathrm{mg} / \mathrm{ml}$ and $0.50 \mathrm{mg} / \mathrm{ml}$ that were used in the study. Similar serial dilutions of acetylcholine were applied to $1 \mathrm{ml}$ of $1.0 \mathrm{mg} / \mathrm{ml}$ of epinephrine. The adrenaline and acetylcholine were used as positive and negative controls in the experimental study respectively.

\section{Harvesting of rabbit heart}

In this experiment, only one viable rabbit heart was used for all the test leaf extract doses, adrenaline and acetylcholine. The animal was put to sleep by injecting $30.0 \mathrm{mg} / \mathrm{kg}$ bwt of sodium pentobarbitone to minimize pain and harm to the animal. The chest of the rabbit was opened immediately and the heart was dissected out with about $1 \mathrm{~cm}$ of the aorta attached. The heart was washed 
as quickly as possible with warm oxygenated Locke solution. It was mounted on the Langendorff's heart perfusion pressure chamber and transducer (Harvard apparatus, Saint Laurent, Quebec) in preparation for heart contractility study. ${ }^{24-26}$

\section{Experimental procedure for heart contractility (force and rate) activity study}

The study was performed according to the Langendorff's heart perfusion methods. ${ }^{24,25}$ The heart was tied to a stainless steel cannula through the aorta. The Locke perfusion fluid (at temperature range of $36.5-37.5^{\circ} \mathrm{C}$ ) was continuously bubbled with a mixture of $95 \%$ oxygen and $5 \%$ carbon dioxide at a constant perfusion pressure of 70 $\mathrm{mmHg}$ and at a temperature between $36.6^{\circ} \mathrm{C}$ and $37.5^{\circ} \mathrm{C}$. The heart was allowed to stabilize for 5 minutes before addition of any drug and the extracts. Recording on the kymograph was done to obtain normal contractility of the heart which was considered as baseline for the different concentrations of the drugs and extracts. Adrenaline was used first in increasing concentrations and each concentration was added after return of contractility to baseline. Adrenaline was followed by the methanol, aqueous, ether and total crude leaf extracts of $V$. amygdalina and lastly with acetylcholine. About $0.2 \mathrm{ml}$ of each drug concentration and the extracts were added using a $1 \mathrm{ml}$ syringe through the perfusion line above the aortic vessel and the changes in the cardiac contraction were recorded using a kymograph and a tracing paper. Each experiment was run for three minutes with a contact time of 5 seconds. The baseline recording before perfusion of a particular drug was considered the baseline reading for each dose. The parameters measured were the heart rate and mean force of contractility of the heart. The different 5 peak heights of the heart contraction were measured as recorded on the kymograph. The peak was measured using a calibrated ruler in millimeters. The heart rate for each dose of the drug was measured by counting the number of heart beats in 15 seconds and the heart beats per minute were then calculated. ${ }^{24,25,29}$

\section{Data management and quality control}

The data for each of the experiment carried out on the heart muscle were recorded for each concentration of each drug and the extracts. The cyclic height was measured at five different points on the kymogram. The mean percentage change in height using the baseline was calculated for each dose used for the plant extract, acetylcholine and adrenaline and this measured the force of contraction of the heart. This was done using the following formula:

Force of contraction $=$ (experimental value - baseline value) $\times 100 /$ baseline value

The rate of the contraction of the heart (heart beats/minute) was recorded. For quality control all the equipment were calibrated to ensure they were efficient before use. The animals (s) that were used in the experiment were in their normal physiological state. The reagents used were of analytical grade. The perfusion fluid (Locke's solution) was maintained at the appropriate temperature $\left(36.5-37.5^{\circ} \mathrm{C}\right)$. Clean syringes were used to administer each drug and extracts.

\section{Data analysis}

Data was analyzed using SPSS version 20. The ANOVA test was used to compare the means within and between groups for the force and rate of contraction of heart for the test doses of each extract and controls and the $p<0.05$ was considered statistically significant.

\section{Ethical consideration}

The permission was obtained from the College of Veterinary Medicine Animal Resource and Biosecurity (CoVAB), Makerere University to carry out the experiment and the animals were treated according to the International guidelines on the laboratory animal use and care protocols of OECD (2001). ${ }^{27}$ The animals were handled with utmost care before the experiment and at the time of the experiment. ${ }^{27,28}$

\section{RESULTS}

The findings show that there was a reduction trend in the mean percentage change of force of heart contractility (inotrophy) with increasing doses of the ether, methanol, aqueous and total crude leaf extracts from $0.5 \mathrm{mg} / \mathrm{ml}$ to $250.0 \mathrm{mg} / \mathrm{ml}$ as compared to the baseline. The findings were similar to that of acetylcholine that was used as a negative control and opposite to that observed with adrenaline which was used as a positive control. However, the doses of pure drugs used in the experiments as controls were lower than those of the leaf extracts of $V$. amygdalina that were used in crude form (Table 1).

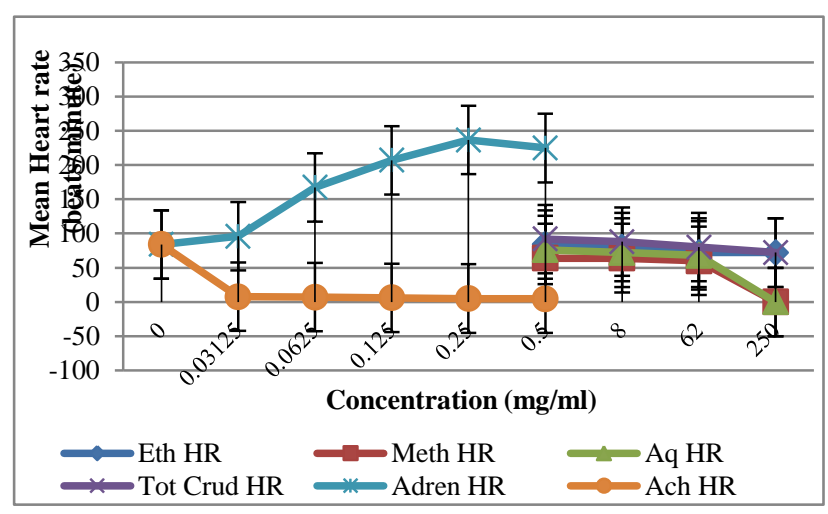

Figure 1: Effects of the different extracts concentrations of $V$. amygdalina on the rate of contraction of the isolated rabbit heart.

Key: Eth HR- ether extract heart rate, Meth HR- methanol extract heart rate, Aq HR- aqueous extract heart rate, Tot Crude HR- total crude extract heart rate, Adren HR- adrenaline heart rate, Ach HR- acetylcholine heart rate. 
For the rate of heart contraction (beats/minute), the findings show a reduction trend with increasing doses of ether, methanol, aqueous and total crude leaf extracts of $V$. amygdalina from $0.5 \mathrm{mg} / \mathrm{ml}$ to $250.0 \mathrm{mg} / \mathrm{ml}$. The findings were similar to that observed with acetylcholine and opposite to that of adrenaline. However, the inotropic and chronotropic effect of the leaf extracts of $V$. amygdalina were observed to be stronger for methanol and aqueous leaf extracts as compared to ether and total crude leaf extracts (Table 1 and Figure 1).

Table 1: Effects of the different extracts concentrations of $V$. amygdalina on the force of contraction of the isolated rabbit heart.

\begin{tabular}{|lllllllll|}
\hline $\begin{array}{l}\text { Dose } \\
(\mathbf{m g} / \mathrm{ml})\end{array}$ & Adrenaline & Ach & $\begin{array}{l}\text { Ether } \\
\text { extract }\end{array}$ & $\begin{array}{l}\text { Methanol } \\
\text { extract }\end{array}$ & $\begin{array}{l}\text { Aqueous } \\
\text { extract }\end{array}$ & $\begin{array}{l}\text { Total crude } \\
\text { extract }\end{array}$ & $\begin{array}{l}\text { Anova } \\
\text { p value }\end{array}$ \\
\hline $\mathbf{0 . 0 3}$ & $96.02 \pm 17.71$ & $-10.1 \pm-7.00$ & - & - & - & - & $\mathrm{p}<0.001$ \\
\hline $\mathbf{0 . 0 6}$ & $167.3 \pm 35.00$ & $-24.76 \pm 0.00$ & - & - & - & - & $\mathrm{p}<0.001$ \\
\hline $\mathbf{0 . 1 3}$ & $206.9 \pm 0.00$ & $-30.7 \pm 0.00$ & - & - & - & - & $\mathrm{p}<0.001$ \\
\hline $\mathbf{0 . 2 5}$ & $236.6 \pm 7.00$ & $-40.6 \pm-71.42$ & - & - & - & $-4.96 \pm-7.00$ & $\mathrm{p}<0.001$ \\
\hline $\mathbf{0 . 5 0}$ & $224.72 \pm 0.00$ & $-58.42 \pm-7.01$ & $-36.64 \pm-4.20$ & $14.84 \pm 0.00$ & $8.90 \pm-0.64$ & -1 \\
\hline $\mathbf{8 . 0 0}$ & - & - & $-38.62 \pm-1.40$ & $8.90 \pm 0.00$ & $-4.78 \pm 0.00$ & $-10.90 \pm-14.01$ & $\mathrm{p}<0.001$ \\
\hline $\mathbf{6 2 . 0 0}$ & - & - & $-40.54 \pm-6.83$ & $-10.90 \pm 0.00$ & $-10.90 \pm 0.00$ & $-20.80 \pm 0.00$ & $\mathrm{p}<0.001$ \\
\hline $\mathbf{2 5 0 . 0 0}$ & - & - & - & $-74.26 \pm-2.80$ & $-100.00 \pm-7.00$ & $-100.00 \pm 0.00$ & $-80.20 \pm 0.00$ & $\mathrm{p}<0.001$ \\
\hline
\end{tabular}

Value shows a reduction in the force of contraction in relation to the baseline.

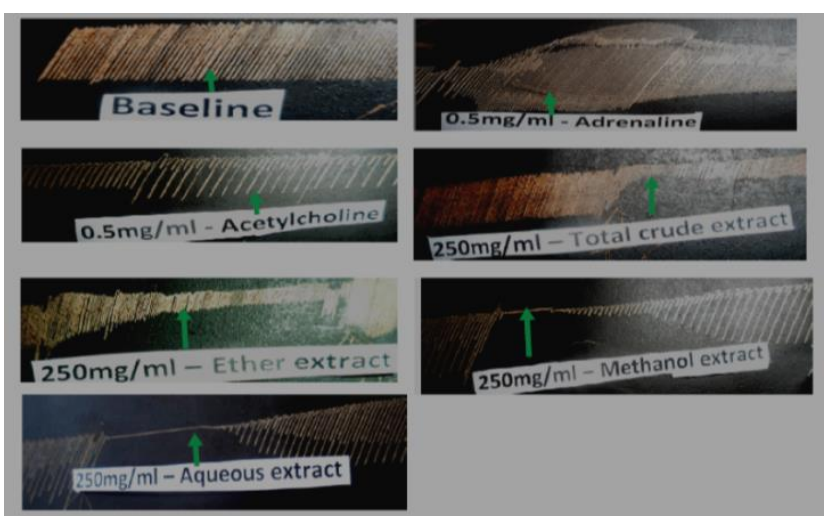

Figure 2: Kymograms of adrenaline, acetylcholine and different doses of ether, methanol, aqueous and total crude extracts of $V$. amygdalina on contractility of the isolated rabbit heart.

Key: Arrow represents the effect of the drug/extract observed after dosing the heart.

The arrows on the kymogram (Figure 2) show the point of contact of drug with the heart muscle and the effect caused by the drug on the heart at that point.

\section{DISCUSSION}

The study investigated the effect of ether, methanol, aqueous and total crude extracts of $V$. amygdalina with adrenaline and acetylcholine as controls on the contractility of an isolated rabbit heart. The findings show that methanol, aqueous, ether and total crude leaf extracts of $V$. amygdalina, a plant commonly used for dietary and medicinal purposes caused an overall dose-dependent reduction in rate and force of contractility of an isolated rabbit heart similar to that observed with acetylcholine. The observed effect could be attributed to by the various phytochemical components including flavonoids, polyphenols like resveratrol, saponins, diosgenin, tocotrienols which is a vitamin $\mathrm{E}$, isothiocyanates like sulforaphane and high $\mathrm{K}^{+}$levels. These compounds have been reported to have an effect on the heart and these could have caused the observed reduction in the force and rate of heart contractility by the different fractions of the extracts of $V$. amygdalina. ${ }^{13-15,18-23}$ The high concentration of potassium ions from the extracts, that is introduced in the heart increases the $\mathrm{K}^{+}$ions outside the cell membrane of cardiac muscle which leads to hyperpolarization of the cells of the myocardium thus preventing depolarization of the cells. ${ }^{23}$ This reduces the electrical impulses generation and passage in the myocardium thus reducing the heart rate and contractility as observed in the experiment. ${ }^{23}$ The higher concentration of potassium ions $\left(\mathrm{K}^{+}\right)$in aqueous and methanol leaf extract of $V$. amygdalina could have contributed to the greater reduction in the heart rate and force of contractility as compared to ether and total crude leaf extracts and possibly to the observed cardiac arrest in the study. ${ }^{15,18,19,21,22,26}$

The ether extract contains only a few phytochemicals in low quantities especially cardiac glycosides which could have minimal reducing effect on the heart hence the reduced observed heart rate and force of contraction. ${ }^{14,29}$ Previous studies have reported that methanol extract contains various phytochemical compounds including saponins, tannins, flavonoids, glycosides, alkaloids, phenolics, reducing sugars, phytosteroids, terpenes, antharacenosides..$^{9,10,14,15,17-19}$ Aqueous extract contains tannins, saponins, flavonoids, cardiac glycosides and alkaloids. ${ }^{9,15,18,19,21,22}$ Ether extract contains saponin, flavonoids, glycosides and alkaloids in low quantities. And these compounds have been reported to have an effect on the force and rate of heart contraction. The leaf extract of $V$. amygdalina has also been reported to contain other various minerals including calcium $\left(\mathrm{Ca}^{2+}\right)$, potassium $\left(\mathrm{K}^{+}\right)$, sodium $\left(\mathrm{Na}^{+}\right)$, magnesium $\left(\mathrm{Mg}^{2+}\right)$ and 
iron $(\mathrm{Fe} 3+)$ in varying quantities, with potassium and calcium ions being higher than sodium, iron and magnesium. ${ }^{9,15,18,19,21,22}$ Variation of these compounds in the methanol and aqueous leaf extracts of $V$. amygdalina caused a greater decrease in rate and force of contractility of the isolated rabbit heart almost leading to cardiac arrest at a dose of $250 \mathrm{mg} / \mathrm{ml}$ unlike the ether and total crude leaf extracts. The reason for the greater decrease in the rate and force of contractility of the isolated rabbit heart with both methanol and aqueous leaf extracts could be that methanol and aqueous extracts contain more phytochemical compounds which could have interacted to bring about the greater decrease in heart rate and force of contraction of the isolated rabbit heart. ${ }^{9,15,18,19,21,22}$

The observed overall decrease in the force and rate of heart contractility of the isolated rabbit heart using the Langendroff's heart perfusion experiment with the ether, methanol, aqueous, and total crude leaf extracts of $V$. amygdalina could have been due to the agonistic effect of the compounds in the leaf extracts that mimicked the physiological effect of acetylcholine, a neurotransmitter released at the parasympathetic nervous system nerve terminals in the heart. ${ }^{23}$ The compounds could also act through inhibition of the sympathetic nervous system a branch of the autonomic nervous system. ${ }^{14,18-20,22,23}$ The compounds that have been reported in $V$. amygdlina leaf extracts that could contribute to the reduced chronotrophic and ionotrophic effects of the heart include, anthraquinones, soluble tannins, alkaloids, flavonoids, indoles, alkaloids, steroidal alkaloids, saponins, condensed tannins, glycosides, cyanogenic glycosides and terpenoids at varying quantities. The leaf extract has also been reported to contain carbohydrates, ascorbic acids, protein, fiber and vitamins in varying quantities. ${ }^{14,18-20,22,23}$

On the other hand, adrenaline released at the sympathetic nerve terminals in the heart muscle cells, increases the cardiac muscle fiber membrane concentrations of sodium and calcium ions by binding to $\beta 1$ adrenergic receptors, which are G-protein coupled receptors leading to stimulation of adenylate cyclase stimulation releasing cyclic adenosine monophosphate (cAMP) a secondary messenger. An increase of sodium and calcium ion permeability causes a more positive membrane resting potential hence bringing it nearer to the threshold level for self-excitation. $^{23}$ In the $\mathrm{A}-\mathrm{V}$ node and $\mathrm{A}-\mathrm{V}$ bundles, increased sodium and calcium permeability increases excitability of each succeeding portion of the conducting fibers, by the action potential hence decreasing conduction time from the atria to the ventricles. ${ }^{23}$ The increase in the permeability of the calcium ions is partially responsible for the increase in the force of contraction of the cardiac muscle because the increased concentrations of calcium ions play a major role in contractile process of myofibrils. ${ }^{23}$ It is also possible that the normal mechanism of the heart contractility could be interfered with the phytochemical components and the high concentration of ions especially $\mathrm{K}+$ ions present in the extracts that caused the observed reduced force and rate of contraction of the heart. ${ }^{21,23}$ The increasing concentrations of adrenaline leads to an increase in the contractility of the heart but overstimulation of heart overworks the heart muscle, leading to decrease in heart contractility and rate (Figure 2). A very high concentration of adrenaline can lead to cardiac arrest or even death of the tissue due to insufficient oxygen and nutrient supply. Acetylcholine on the other hand decreases the rate of rhythm of the sinus node and decreases the excitability of the A-V node junction fibers between the $\mathrm{A}-\mathrm{V}$ node and the atria hence slowing passage of impulses in the heart. ${ }^{23}$

The acetylcholine increases the permeability of the fiber membranes to potassium ions leading to rapid leakage of potassium out of the conductive fibers. This makes the fibers hyperpolarized making them much less excitable. ${ }^{23}$ This then decreases the force and rate of heart contractility. In the sinus node, hyperpolarization decreases the resting membrane potentials requiring more time to reach the threshold for excitation. ${ }^{23}$ At high concentrations of acetylcholine it's possible to stop entirely the rhythmical self-excitation of the sinus node. In the A-V node, hyperpolarization makes it difficult for atrial fibers entering the node to excite the nodal fibers while the low concentration blocks conduction entirely. The results therefore show that methanol, ether, aqueous and total crude leaf extracts of $V$. amygdalina contains various phytochemical compounds and minerals such as potassium ions that may have caused the hyperpolarization of the myocardial cell membrane and hence causing a reduced inotropic and chronotropic effects on the heart and hence its increased use by the local communities and traditional herbalists in Uganda in management of heart diseases especially hypertension.

\section{CONCLUSION}

The methanol, ether, aqueous and total crude leaf extracts of $V$. amygdalina contain active compounds and minerals that decreased the rate and force of contractility of an isolated mammalian heart. The effect of the methanol and aqueous leaf extracts of $V$. amygdalina on rate and force of contractility of the isolated perfused rabbit heart was more than that of ether and total crude leaf extracts.

\section{ACKNOWLEDGEMENTS}

I appreciate the technical personnel who supported the study especially the experimental laboratory work.

\section{Funding: No funding sources \\ Conflict of interest: None declared \\ Ethical approval: The study was approved by the Institutional Ethics Committee}

\section{REFERENCES}

1. IARC. History of Use of Traditional Herbal Medicines. IARC Monographs, International Agency for Research on Cancer (IARC). 2018;82:43-66. 
2. Rastogi S, Pandey MM, Rawat AKS. Traditional herbs: a remedy for cardiovascular disorders. Phytomedicine. 2016;23(11):1082-9.

3. WHO. Global Atlas on cardiovascular disease prevention and control. World Health Organization (WHO), Geneva, Switzerland in collaboration with the World Heart Federation and the World Stroke Organization. 2011: 1-166. Available at: https://apps.who.int/iris/bitstream/handle/10665/4470 1/9789241564373_eng.pdf?sequence=1. Accessed on 3 January 2019.

4. WHO. Non-Communicable Disease Risk Factor Baseline Survey: Uganda 2014 Report. World Health Organization (WHO), Geneva, Switzerland. 2014: 1206. Available at: https://www.who.int/ncds/ surveillance/steps/Uganda_2014_STEPS_Report.pdf. Accessed on 3 January 2019.

5. WHO. Cardiovascular diseases (CVDs) Fact sheet. World Health Organization (WHO), Geneva, Switzerland. 2019. Available at: https://www.who. int/news-room/fact-sheets/detail/cardiovasculardiseases-(cvds). Accessed on 7th August 2019.

6. WHO. Types of cardiovascular disease. World Health Organization (WHO), Geneva, Switzerland. 2019: 1. Available at: https://www.who.int/ cardiovascular_diseases/en/cvd_atlas_01_types.pdf?u $\mathrm{a}=1$. Accessed on 7th August 2019.

7. Ruan Y, Guo Y, Zheng Y, Huang Z, Sun S, Kowal P, et al. Cardiovascular disease (CVD) and associated risk factors among older adults in six low-and middle-income countries: results from SAGE Wave 1. BMC Public Health. 2018;18:778.

8. Lunyera J, Kirenga B, Stanifer JW, Kasozi S, Molen T, Katagira W, et al. Geographic differences in the prevalence of hypertension in Uganda: Results of a national epidemiological study. PLoS ONE. 2018;13(8):e0201001.

9. Baharvand-Ahmadi B, Bahmani M, Eftekhari Z, Jeloda M, Mirhoseiniri M. Overview of medicinal plants used for cardiovascular system disorders and diseases in ethnobotany of different areas in Iran. J HerbMed Pharmacol. 2016;5(1):39-44.

10. Egharevba C, Osayemwenre E, Imieje V, Ahomafor J, Akunyuli C, Udu-Cosi AA, et al. Significance of Bitter Leaf (Vernonia Amagdalina) In Tropical Diseases and Beyond: A Review. Malaria Chemotherap Control Elimination. 2014;3(1):1-10.

11. Namukobe J, Kasenene JM, Kiremire BT, Byamukama R, Kamatenesi-Mugisha M, Krief S, et al. Traditional plants used for medicinal purposes by local communities around the Northern sector of Kibale National Park, Uganda. J Ethnopharmacol. 2011;36(2011):236-45.

12. Tugume P, Kakudidi EK, Buyinza M, Namaalwa J, Kamatenesi M, Mucunguzi PC, et al. Ethnobotanical survey of medicinal plant species used by communities around Mabira Central Forest Reserve, Uganda. J Ethnobiol Ethnomed. 2016;12(5):1-28.

13. Alara OR, Abdurahman NH, Ukaegbu CI, Kabbashi NA. Extraction and characterization of bioactive compounds in Vernonia amygdalina leaf ethanolic extract comparing Soxhlet and microwave-assisted extraction techniques. J Taibah Univ Sci. 2019;13(1):414-22.

14. Inusa A, Sanusi SB, Linatoc AC, Mainassara MM, Awawu JJ. Phytochemical analysis and antimicrobial activity of bitter leaf (Vernonia amygdalina) collected from Lapai, Niger state, Nigeria on some selected pathogenic microorganisms. Sci World J. 2018;13(3):15-8.

15. Vasanthi HR, ShriShriMal N, Das DK. Phytochemicals from plants to combat cardiovascular disease. Current Med Chem. 2012;19(14):2242-51.

16. Garba ZN, Oviosa S. The effect of different drying methods on the elemental and nutritional composition of Vernonia amygdalina (bitter leaf). J Taibah Univ Sci. 2019;13(1):396-401.

17. Shewo BS, Girma B. Review on Nutritional and Medicinal Values of Vernonia amygdalina and its Uses in Human and Veterinary Medicines. Global Veterinaria. 2017;19(3):562-8.

18. Agomuo JK, AkajiakuL O, AlakaI C, Taiwo M. Mineral and anti-nutrients of fresh and squeezedwashed bitter leaf (Vernonia amygdalina) as affected by traditional de-bittering Methods. Eur J Food Sci Technol. 2016;4(2):21-30.

19. Alara OR, Abdurahman NH, Mudalip SKA, Olalere OA. Phytochemical and Pharmacological properties of Vernonia amygdalina: A Review. J Chem Eng Industrial Biotechnol (JCEIB). 2017;2:80-96.

20. Igile GO, Iwara IA, Mgbeje BIA, Uboh FE, E EP. Phytochemical, Proximate and Nutrient Composition of Vernonia calvaona Hook (Asterecea): A GreenLeafy Vegetable in Nigeria. J Food Res. 2013;2(6):111.

21. Oseni K, Babatunde O. Vernonia amygdalina: An Underutilized Vegetable with Nutraceutical Potentials - A Review. Turkish J Agriculture Food Sci Technol. 2016;4(9):763-8.

22. Adewole E, Ojo A, Ogunmodede OT, Adewumi DF. Antioxidant Activities and Nutritional Compositions of Vernonia amygdalina. Int J Basic Applied Sci. 2015;4(1):9-16.

23. Shattock MJ, Ottolia M, Bers DM, Blaustein MP, Boguslavskyi A, Bossuyt $J$, et al. $\mathrm{Na}+/ \mathrm{Ca} 2+$ exchange and $\mathrm{Na}+/ \mathrm{K}+/$-ATPase in the heart. J Physiol. 2015;593(Pt 6):1361-82.

24. Dhein S. The Langendorff Heart, In: Dhein S, Mohr FW, Delmar M. (eds): Practical Methods in Cardiovascular Research. Research Springer, Berlin, Heidelberg. 2005:155-72.

25. Lateef RU, Al-Masri AA, Alyahy AM. Langendorff's isolated perfused rat heart technique: a review. Int $\mathbf{J}$ Basic Clin Pharmacol. 2015;4(6):1314-22.

26. Shatoor AS. Cardio-tonic effect of the aqueous extract of whole plant of Crataegus aronia syn: azarolus (L) on isolated Rabbit's heart. Afr J Pharm Pharmacol. 2012;6(26):1901-9.

27. OECD. Acute Oral Toxicity Fixed Dose Procedure : OECD/OCDE 420. Organisation for Economic Co- 
operation and Development (OECD). 2001:1-14. https://ntp.niehs.nih.gov/iccvam/suppdocs/feddocs/oe cd/oecd_gl420.pdf. Accessed on 3 January 2019.

28. NIH. Guide for the Care and Use of Laboratory Animals. National Research Council of the National Academies Press Washington DC: 2011: 8ed. http://grants.nih.gov/grants/olaw/Guide-for-the-careand-use-of-laboratory-animals.pdf. Accessed on 3 January 2019.

29. Nalumansi O, Bbosa GS, Lubega A, Onegi B. Fresh and Decayed Stem Juice of Musa acuminata $x$ balbisiana (Musa paradisiaca) Reduce the Force and Rate of Contractility of an Isolated Perfused Rabbit Heart. Br J Pharm Res. 2014;4(9):1105-15.

Cite this article as: Bbosa GS, Lubajo R, Lubega AM, Odia G, Katerega J. Effects of leaf extracts of Vernonia amygdalina on the force and rate of contractility of an isolated mammalian heart. Int $\mathbf{J}$ Basic Clin Pharmacol 2019;8:2389-95. 